\title{
The Analysis of the Illuminance Level in the Workspace, Using Natural and Artificial Lighting in Graha Pena Building in Makassar, Indonesia
}

\author{
Nurul Jamala $^{1^{*}}$, Ramli Rahim ${ }^{1}$, Taufik Ishak ${ }^{1}$, Sharyzee Mohamad Shukri ${ }^{2}$ \\ ${ }^{1}$ Department Architecture, Engineering Faculty, Hasanuddin University, Indonesia \\ ${ }^{2}$ Faculty of Architecture and Build Environment, Infrastructure University Kuala Lumpur, Malaysia \\ *nuruljamala@yahoo.co.id
}

Energy-efficient building design models are one of the factors that need to be considered in building planning. In the morning to evening, sunlight as a source of natural light can be used as a source of lighting in buildings. By utilizing natural light, it will reduce energy consumption in buildings. Air conditioning and lighting are important factors in designing energy efficient buildings. In this study, analyzing natural and artificial lighting at Graha Pena Makassar Building. The research method is quantitative by measuring and analyzing several workspaces that are directly and indirectly related to openings in the building envelope. statistical descriptive analysis, namely entering data into tables and graphs, then analyzing the level of illumination in the analyzed workspace. The research objective was to determine the level of illuminance in several workspaces with different orientations. How is the effect of natural light distribution on building orientation and how is the artificial lighting system at workspace in the Graha Pena Makassar. The results showed that the orientation of the building had an effect on the distribution of natural light into the space. The spatial orientation facing East has a higher distribution of natural light than that of the south. Workspaces that are not directly related to window openings in the building envelope are using artificial lighting systems in the form of lights. The workspace has uneven illumination levels in its work area, because the layout and placement of lighting points have not been well planned. The contribution of this research is a reference in designing a building facade design with an attractive appearance, and can maximize the use of solar energy as a source of natural lighting, while still paying attention to the visual comfort of space users.

Keywords: Illuminance Level, Natural Light, Artificial Light

1 Journal of Design and Built Environment, Vol 21(1) 1-12, April $2021 \quad$ Nurul Jamala. et al. 


\section{INTRODUCTION}

The optimization of lighting systems in buildings is to consider the integration between natural light and artificial light. Maximize the use of natural light into the room, can minimize energy consumption as an artificial lighting source. Some considerations of negative effects, in the use of natural light include: thermal, glare, ratio and the value of brightness.

An understanding of the luminance distribution is very much needed as a reference in building lighting planning. The International Commission de IEclairage (CIE) which has approved two international standards on the distribution of standard sky luminance (1955) cloudy sky and clear sky (1973). Rahim R (2007) stated that Intermediate sky condition, namely the condition of the sky between clear sky and cloudy sky, can be found from various parts of the earth, especially in the equatorial hemisphere.

The floor height of building and sky condition affect the distributions of light come into the room. The window opening on the building envelope have effect on the illuminance level in the building (Jamala N, 2019). The distribution of light enters the space higher in the area near the building envelope. Natural light distribution affects the height of the building's floor and the dept of space in the building (Jamala N, 2019). The level of illuminance spread across several countries among others: Darwin/ Australia at $12.7 \mathrm{klx}$ (Ruck, 1985), Japan to $13.5 \mathrm{klx}$ (Nakamura, 1979), Bandung/ Indonesia to 10.0 klx (Adiwijoyo, 1969), Makassar/ Indonesia (Rahim R, 2004) at $14.3 \mathrm{klx}$ and Hong Kong at $8.5 \mathrm{klx}$ (Lau, et al., 2007).

One of the tallest buildings in Makassar is the Menara Phinisi Makassar which has a diagonal and horizontal facade on the building's envelope, so there is no glare and brightness in space. This building is one example of building in designing high building. In terms of aesthetics, building facade is a positive value but needs to be considered the visual comfort of space users so that work productivity can have increased (Jamala N, 2017).

The Standard recommendation of illuminance levels in the office room are based on recommendation value by CIE (Commision International de I'Elaire) and IES (Illuminating Enginers Society). These recommendations are national and international standards of illuminance levels for design lighting (UNEP, 2006). Building lighting design is designed based on the illumination standard recommended by SNI 03-6575-2001. Illumination value in the workspace is 350 lux and meeting room is 500 lux the distribution of light in the buildings, can be influenced by the conditions of the sky, position, area and shape of window openings. Based on this recommendation, the designer can determine the number of armature needed in the space, according to the activity in the space.

According to Nurul (2012) that although it does not meet these standards, space users can still do their activities well. Based on this, it is necessary to study the distribution of natural lighting in selected objects. Newsham et al. (2004) examined quantitative value guidelines, luminance and ratio in office buildings. According to Tomy et al. (2002) stated that the illumination distribution of light in an open plan office using general lighting and light luminance distribution suitability. According to Satwiko (2009), Indonesia is a humid tropical climate with relatively high characteristics of humidity $(60 \%-80 \%)$, high radiation ( $80 \%$ per year), and wind speed (velocity) unstable (between 0-> 30 $\mathrm{m} /$ city seconds). Nakamura et al. (1985) have classified into three groups sky condition i.e. overcast, clear and intermediate sky, trying to define the luminance distribution of the intermediate sky.

Rahim et al (2014) show that the investigated the accuracy of daylight and solar radiation data gathered during 1995-2000 by comparing data measured from two different sources above. The results of both methods are relatively similar, which indicate that daylight and solar radiation data gathered in Makassar are accurate and useful for various daylight designs and applications.

Local Government Rules number 38 (2012) explained that the building envelope is a building element that surrounds the building. They are transparent or not transparent walls or the roof.

Well-thought-out high rise building construction would result in a comfortable living space by using less resources. For example, a biologicallybased building might be so inexpensive and effective that it would need just one tenth of the energy usage the majority of the extra energy used in the biotic building would be recouped within three to five years, does the need for extensive artificial lighting much reduce (Rao SP, Aminuddin Asrul et al, 2012).

Excessive energy use may be linked to geological phenomena: There is a large amount of study on the impact of individual buildings on natural forces Previous studies on skyscrapers have shown that they commonly have particular aims related to electricity use (Aminuddin. Asrul et al., 2012). The study projects related to high-floors has risen dramatically and researchers are giving more focus to studies on the atmosphere of high- 
floor properties as explained by researchers (Shila sharif et. a 2017 and Bano F 2020). There are a few different analyses on how environmental factors affect high-rise buildings. The vast majority of the studies investigate these three big issues: the atmosphere, energy use, and architecture.

Aminuddin A. (2014) examined environmental efficiency on high-rise office buildings with regards to the urban contextsuch as found in Malaysia. An effort was done by Law (2002) which looked at Yeang high-designed skyscrapers efficiency. An investigation, conducted by Syed Fadil and Sheau (2003), dealt with the dynamics of sunshine and daylight delivery. A Salleh (2005), who researched the effect of sustainable high-rise construction on the climate in Malaysia, performed a fifth investigation. This research came to the conclusion with the assistance of several glazing techniques used in tropical locations may also assist to improve the illuminance level.

\section{METHODS}

This research uses quantitative methods that describe the measurement point in wosrkspace. Measurement result data are enteret in form of tabel, bar charts and graphs. Then the analized data level of illuminance in workspace.

The object of the research is the Graha Pena Makassar building. This building, consisting of 1-5 floors as a podium and floors 6-19 as a tower. This building has only amount of 17 floors, because the 13th and 14th floor notations are not used. The object of research is located on the 18th floor, which functions as a workspace of various companies. The oval-shaped building model and the building envelope in the form of glass. On the 18th floor there is a workspace and meeting room. Some of these workspaces only use artificial light and some are directly related to natural light. In this study, analyzing the utilization of natural lighting, namely meeting rooms (Room 1), workspace (Room 2, 3 and 4). Next is the analysis of artificial light in Zone A and B workspaces.

Measurements were made during the day between 10:00 am and 4:00 pm of September 2019. Day light outdoor of Illuminance level at measuring of the mean is 30.000-50.000 lux. Measurements are made at the planned point of measurement 3 times in each measurement point. Measurement using a lux meter to determine the value of the level of illuminance at the planned measurement point in each room.

\section{RESULTS AND DISCUSSION}

The analyzing of measurement results of level illuminance in the several room space so that it can be concluded how the distribution of light come in to the building. Analysis of the level of illuminance in the workspace that only uses artificial light. Furthermore, the analysis of the effect of building orientation on the distribution of natural lighting and analysis of the placement of artificial lighting so that the level of illumination is evenly distributed in the workplace. The following figure 1 shows the Graha Pena Makassar building located on Urip Sumihardjo street. The area is $1,021 \mathrm{Ha} \mathrm{m} 2$ and the building area is $30,308 \mathrm{~m} 2$.
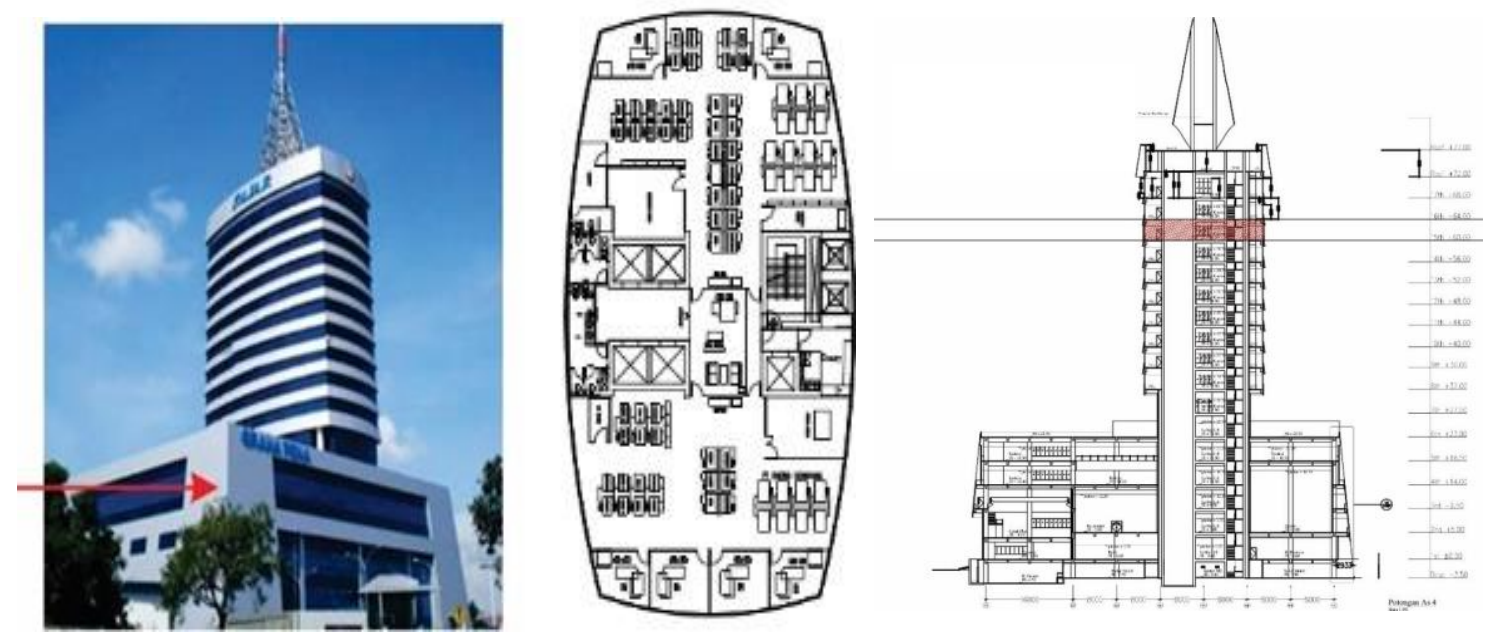

Fig. 1: Floor plan of Graha Pena Building in Makassar 
On the 18th floor there are several work rooms, meeting rooms and support rooms. Measurements are only made in meeting rooms (Room 1), workspaces (Room 2, 3 and 4), as well as Zone A and B workspaces (Figure 2). The basis for selecting the space is spaces Room $1,2,3$ and 4 utilizing the distribution of natural lighting with different room orientations, while Zone A and B rooms only use artificial lighting. Measurements were made 5 times at each point and carried out in the morning (10:00 to 11:00), afternoon (13:00-14:00) and in the afternoon (16.00-17.00). The space plan selected as the object of research is shown in Figure 2 below.

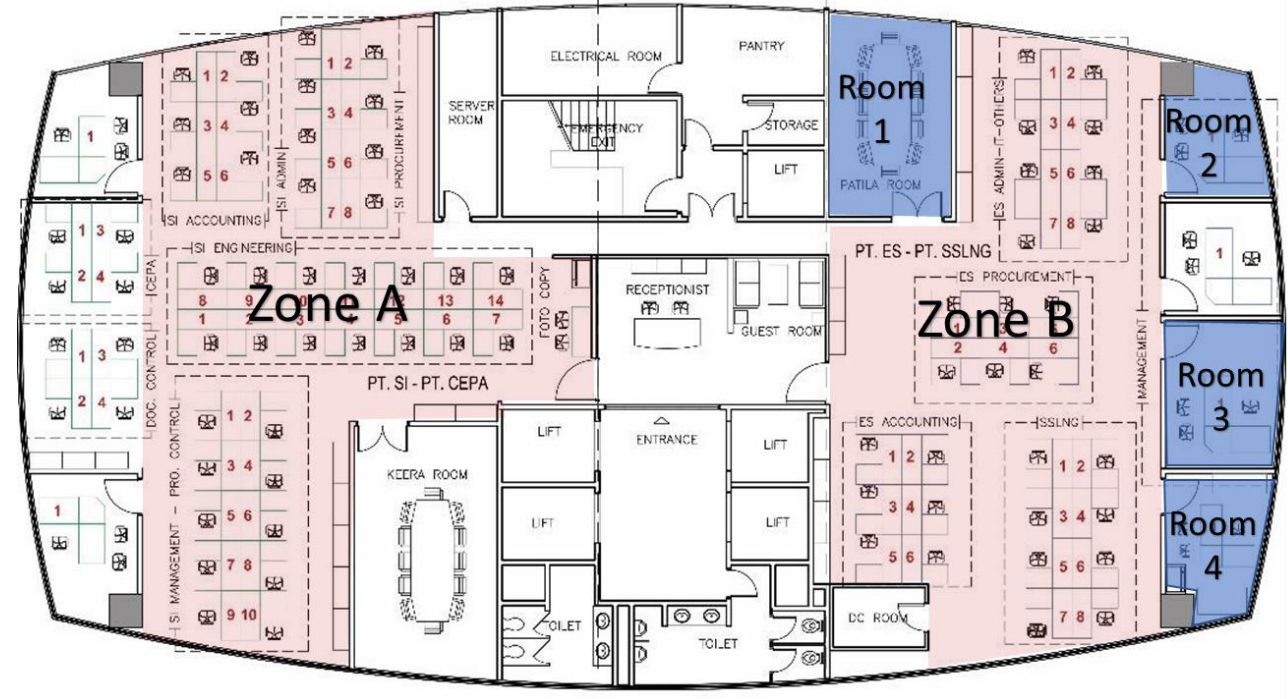

Fig. 2: Floor Plan of Graha Pena Building on $18^{\text {th }}$ floor

\subsection{Analisys of Illuinance Level of Meeting Room (Room 1)}

Room 1 is a meeting room that has one side of the wall that is directly related to natural lighting. This meeting room is oriented towards the east and measures $\pm 25 \mathrm{~m} 2$ and a height of 2.80 meters. This analysis is to find out how the distribution of light come in to the room and how the influence of the depth of space on the distribution of natural lighting. Figure 3 below shows the condition of the meeting room and the placement of the measuring points. The distance of the measuring point is $50 \mathrm{~cm}$ from the building envelope using the notation A1-A3, and B1-B3. The A1-A3 measuring point is an area that is directly related to the window openings on the building envelope, so that natural lighting can be utilized in this space.

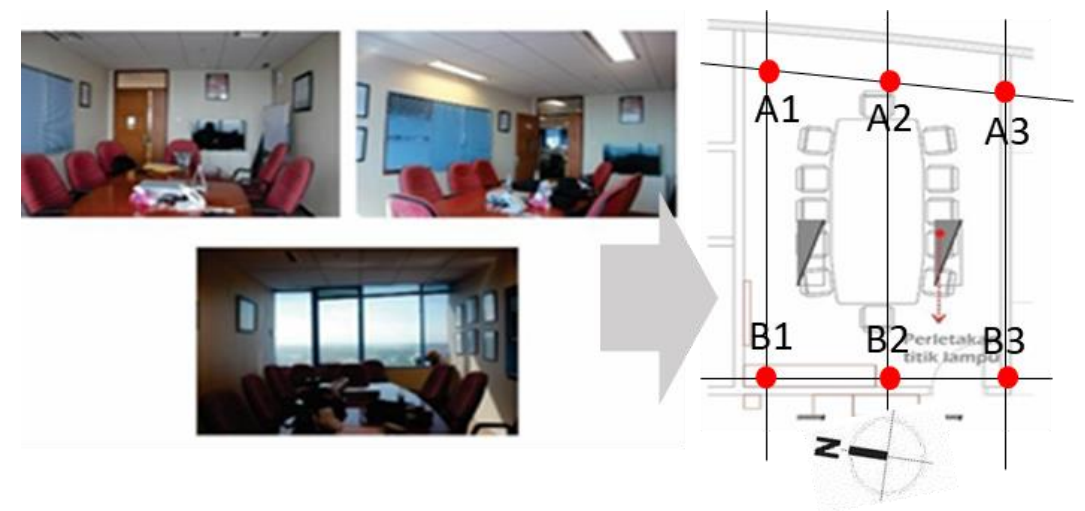

Fig. 3: Conditions and placement of measuring points in meeting rooms (Room 1)

Figure 4 shows a graph of illuminance values in the morning, afternoon and evening. The average value of measurements made for 5 days, namely (a) morning: measuring point at the A1-A3 is 864 lux and B1-B3 is 154 Lux; (b) noon: measuring point A1-A3 is 1068 lux and B1-B3 is 178 lux and; (c) afternoon: measuring point A1-A3 is 535 lux and B1-B3 85 lux. The measurement point on the inside of the room has a low value illuminance, namely point B1-B3 is 154 lux (morning), 178 lux (noon) and 85 lux (afternoon). This graph shows that the highest 
illuminance value is 1068 lux and the lowest is 85 lux. this, an increase in the level of illumination from morning to afternoon by $23.6 \%$ and a decrease of $90.6 \%$ into the afternoon. The results of the analysis showed that in the orientation of the building towards the east, there will be a decrease in the distribution of light in the afternoon, because the sun will sink westward.
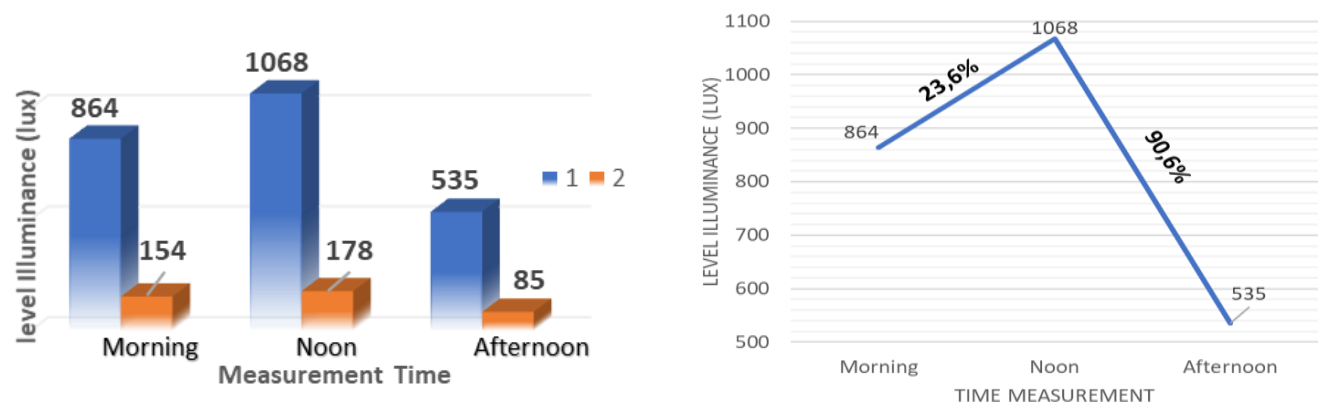

Fig. 4: Line and bar chart of illuminance values in meeting rooms (Room 1)

\subsection{Analisys Illuminance Level Of Workspace (Room 2)}

Room 2 is a personal workspace. This room has openings in the form of dead glass on the veil of buildings as much as two sides, which are predominantly oriented towards the south, but there are also openings to the east. This work area is $\pm 12 \mathrm{~m} 2$. In this room only uses a natural lighting system, but there is also artificial lighting (Fluorescent lamps). Design Placement of the measuring point uses notation A1-A3 and B1-B3, which is located in the area of the building envelope (figure 5).
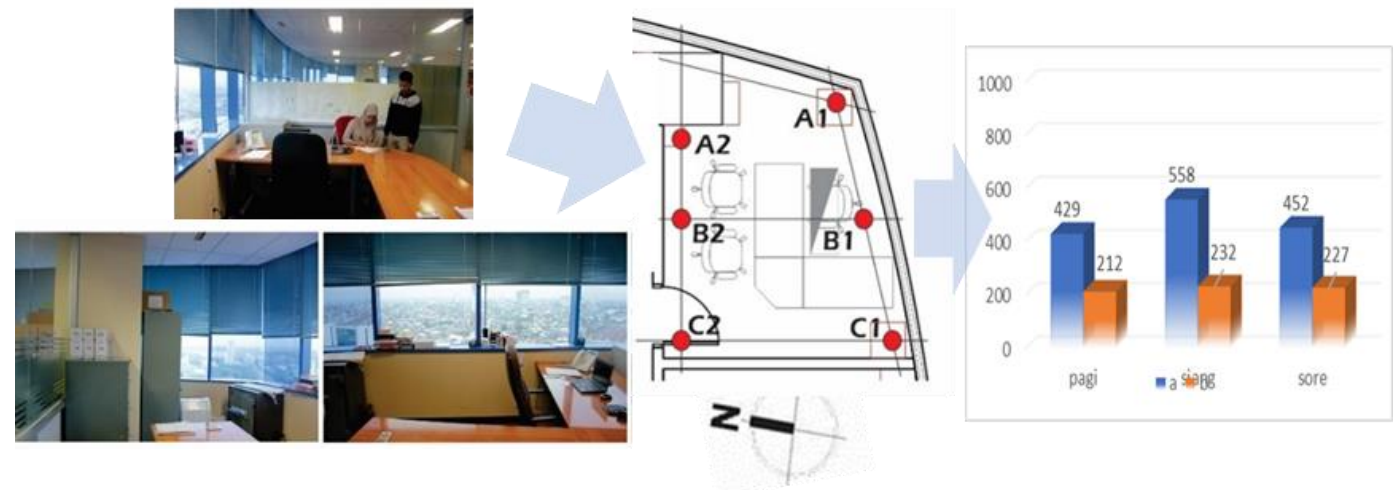

Fig. 5: llumination Conditions and Values in workspaces (Room 2)

Figure 6 shows a graph of measurement results. The maximum illuminance value is 564 lux (point A/daytime) and a minimum of 227 lux (point $\mathrm{B} /$ morning). The illuminance value at point A-A3 from morning to evening is 487 lux, while B1-B3 is 255 lux. The measurement results also show that there is a decrease in the level of illumination from measuring point $\mathrm{A}$ to $\mathrm{B}$, namely $104 \%$ (morning) $111 \%$ (daytime) and $60 \%$ (afternoon). The mean value decreased from point A to B by $90 \%$. This shows that the depth of space is very influential on the value of room illumination. Furthermore, in the area of the building envelope there is an increase and a decrease in the level of illumination from morning to afternoon. The level of illumination from morning to afternoon increases by $22 \%$ and decreases by $30 \%$ into the afternoon. The results of the analysis concluded that the orientation of the building towards the south, had no effect on the distribution of light in the morning, afternoon and evening, because only a minimal difference occurred between $22-30 \%$ in the morning to the afternoon. 

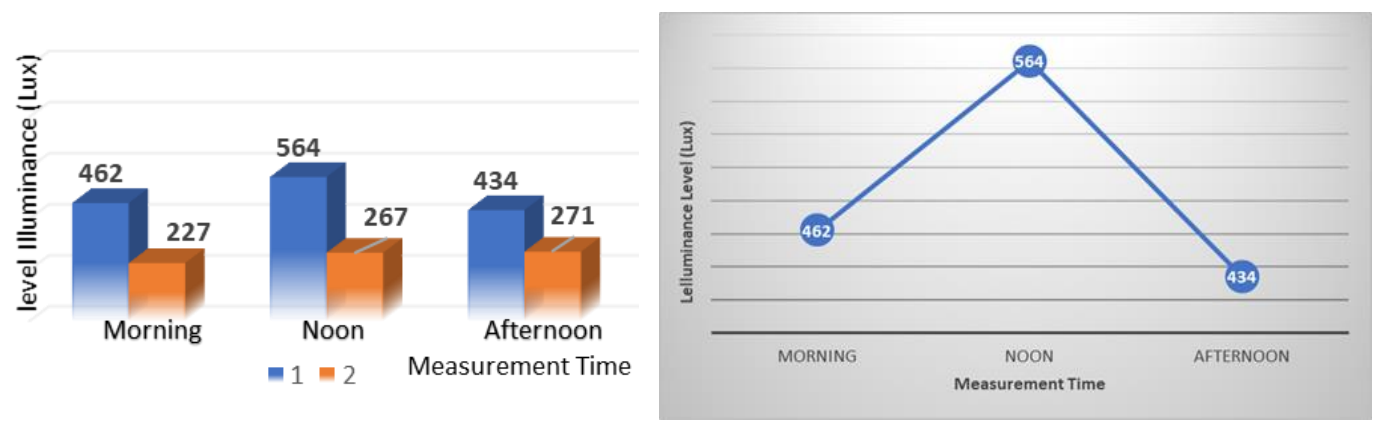

Fig. 6: Linear and bar graphs on illuminance values in workspace (Room 2)

\subsection{Analysis Illuminance Level of Workspace (Room 3)}

Room 3 is a management workspace that functions as a personal workspace. This room is oriented to the south with a $15 \mathrm{~m} 2$ room area which is equipped with a desk and chair and a filing cabinet. This workspace has six measuring points. The measuring points that are close to the window openings are points $\mathrm{A} 1, \mathrm{~B} 1$ and $\mathrm{C} 1$, while the measuring points far from the openings are $\mathrm{A} 2, \mathrm{~B} 2$ and $\mathrm{C} 2$.
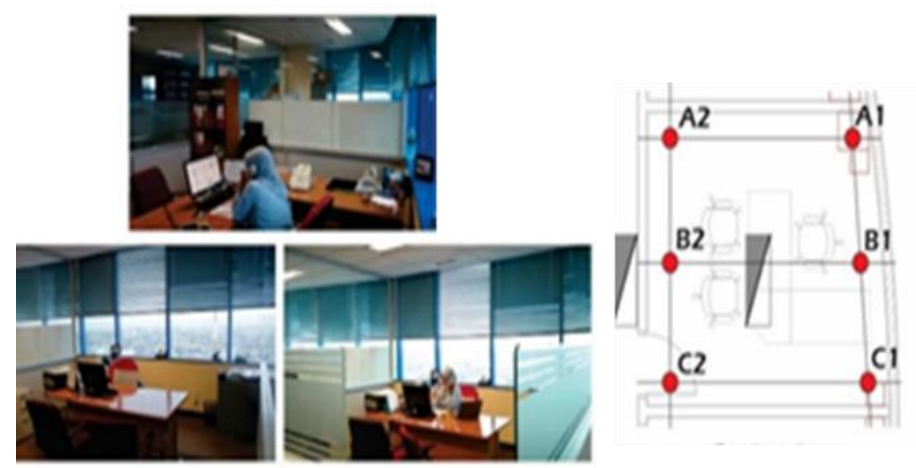

Fig. 7: Existing conditions, layout plans and placement of room 3 space measuring points

Workspace (Room 3) is a personal workspace oriented towards the south. Figure 8 shows a graph of illuminance values in room type 3 . The maximum is 475 lux and a minimum of 193 lux. The average value of illuminance level in the opening area of the building envelope is 386 lux (measuring point A1-A3) and 212 lux (measuring point B1-B3). This shows that the decrease in illuminance value at point A to point B was $82 \%$. The results of the analysis show that the level of illumination in space oriented towards the south is lower in the light distribution when compared to the orientation of space towards the East.

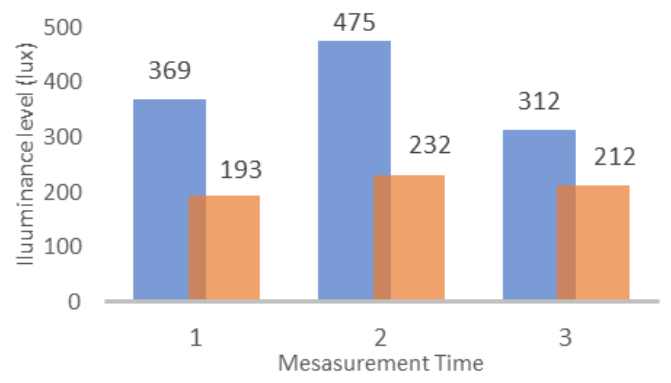

Fig. 8: Bar chart graph Illuminance value in

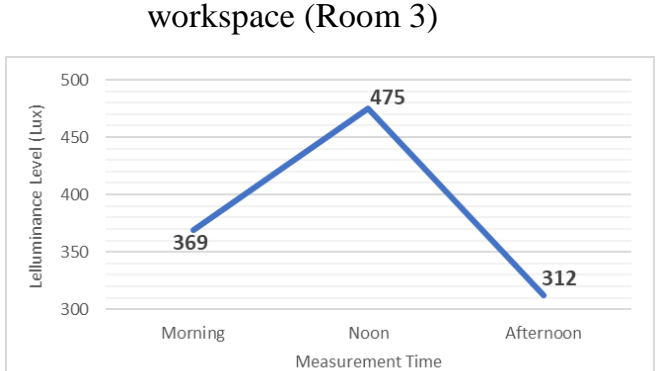

Fig. 9: Linear graph Illumination value in the area of the building envelope (Room 3)

\subsection{Analisys Illuminance Level Of Workspace (Room 4)}

Workspace (Room 4) is a personal workspace on the $18^{\text {th }}$ floor. Light distribution in this room, a maximum of 558 lux at point $\mathrm{A}$ in the afternoon and a minimum of 212 lux at point $B$ in the morning. This space is located in an area that is directly related to the building envelope in the form of glass material. This space is predominantly oriented towards the south, but there are also openings to the east. The analysis 
shows that the distribution of light affects the orientation of the building. The orientation of the sun is rising from the east and setting in the west, so that space oriented towards the south cannot maximize the distribution of light.
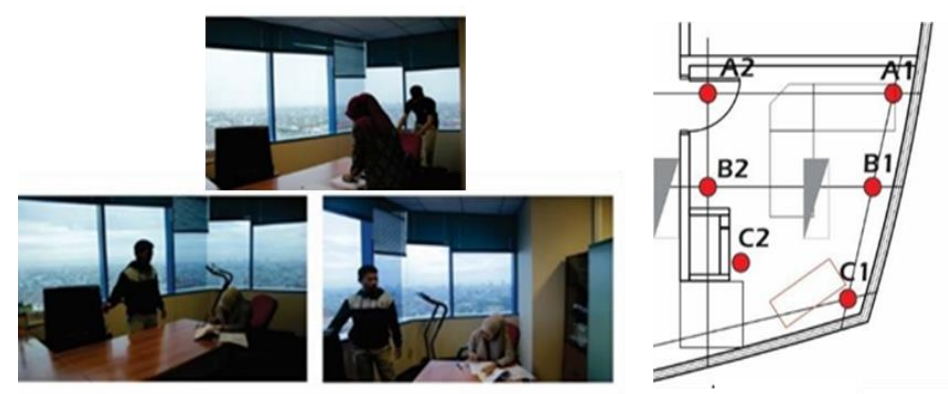

Fig. 9: The mean of illuminance level in Workspace (Room 4)

Figure 10 shows the condition of Room 4 and a graph of the illuminance value of the measurement results. A decrease from point A to $\mathrm{B}$ is $102 \%$ in the morning, $141 \%$ in the afternoon and $99 \%$ in the afternoon. This percentage shows a value that is close to the same. This analysis, shows that the south-west orientation of the light distribution is lower than that of the east-oriented space.

\subsection{Comparative Analysis of the Level Illuminance in Workspace Room 1, 2, 3 And 4.}

From the four results of the analysis on workspace 1, 2, 3 and 4 rooms show that the distribution of light entering the space affects the orientation of the space. The distribution of light oriented towards the east is higher than the orientation towards the south. Based on the results of the analysis also shows that the distribution of light is high when the level of illuminance outdoors in clear or intermediate Sky conditions. The distribution of light is only relatively high in areas close to openings in the building envelope, but the further away from the building envelope there is a decrease in light distribution. The results of this study also indicate that the level of illuminance along the building envelope openings has an illumination value in excess of the recommended SNI 036575-2001 illuminance standards, especially on research objects in the Graha Pena Makassar building. Some things to note are the need for obstructions in the area near the building envelope to prevent glare and brightness. Another alternative is that the arrangement of lay out furniture for the work field is not placed in areas close to the building envelope. Comparison of light distribution in the four spaces, shown in Figure 11 below.

Tabel 1. llumination values in rooms 1-4 in the morning, afternoon and evening

\begin{tabular}{|l|c|c|c|c|c|c|c|c|}
\hline & \multicolumn{2}{|c|}{ Morning } & \multicolumn{2}{c|}{ Noon } & \multicolumn{2}{c|}{ Afternoon } & \multicolumn{2}{c|}{ Mean } \\
\hline Room 1(West) & A1-A3 & B1-B3 & A1-A3 & B1-B3 & A1-A3 & B1-B3 & A & B \\
\cline { 2 - 10 } & 864 & 154 & 1068 & 178 & 535 & 85 & 822 & 265 \\
\hline Room 2 (South-West) & 462 & 227 & 564 & 267 & 424 & 271 & 483 & 237 \\
\hline Room 3 (South) & 369 & 193 & 475 & 232 & 312 & 212 & 385 & 146 \\
\hline Room 4 (South-East) & 429 & 212 & 558 & 232 & 452 & 227 & 480 & 76 \\
\hline
\end{tabular}

Table 1 shows the illuminance values in room 1-4 in the morning until the afternoon. This table shows the illuminance values in the area around the natural light distribution area at point A1-A3. The maximum illuminance value at the A1-A3 measuring point is 1068 lux in room 1 (west) space and the lowest at the A1-A3 measuring point is 312 lux in room 3 (South). This table also shows the illuminance value in an area far from the building envelope, which is the measuring point B1-B3 maximum value of 271 in room type 2 (South-west) and a minimum of 85 lux in room type 1 (west). Data analysis shows that the orientation of the north direction distributes more natural light than the south direction. This analysis also shows that the depth of space is very 
influential on the distribution of light, the further the lower the light distribution. away from the openings as the building envelope,

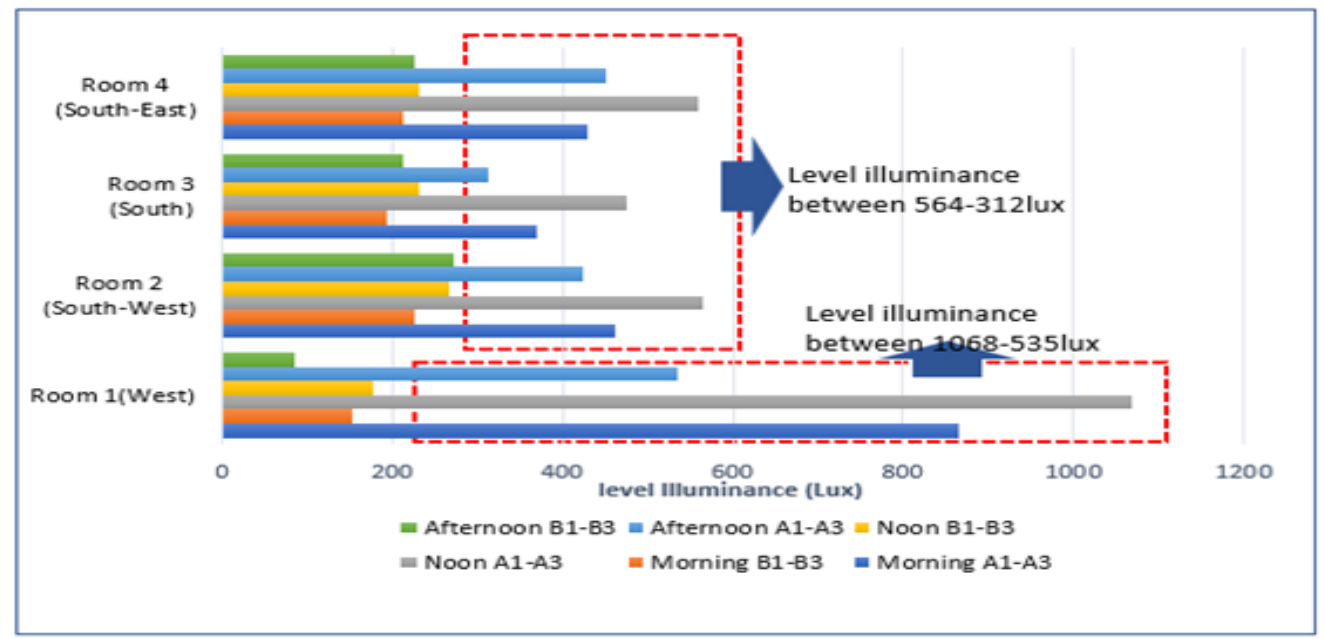

Fig. 10: Graphic comparison of illuminance values in workspace (Room 1-4)

Figure 10 shows a graph of illuminance values in room 1, 2, 3 and 4. The distribution of light in room 1 has the highest illuminance value compared to rooms 2.3 and 4 . This assessment is based on the illuminance value in room 1 spaces between 1068-535 lux while type 2, 3 and 4 rooms are only 564-312 lux. Type 1 spaces are oriented eastward while type 2, 3 and 4 spaces are directed south. Based on this analysis it can also be seen that the orientation of the building influences the distribution of light entering the building. Figure 11 below also shows the level of illuminance in the four work rooms on the 18th floor, which utilizes the distribution of light as a source of lighting in the work area.

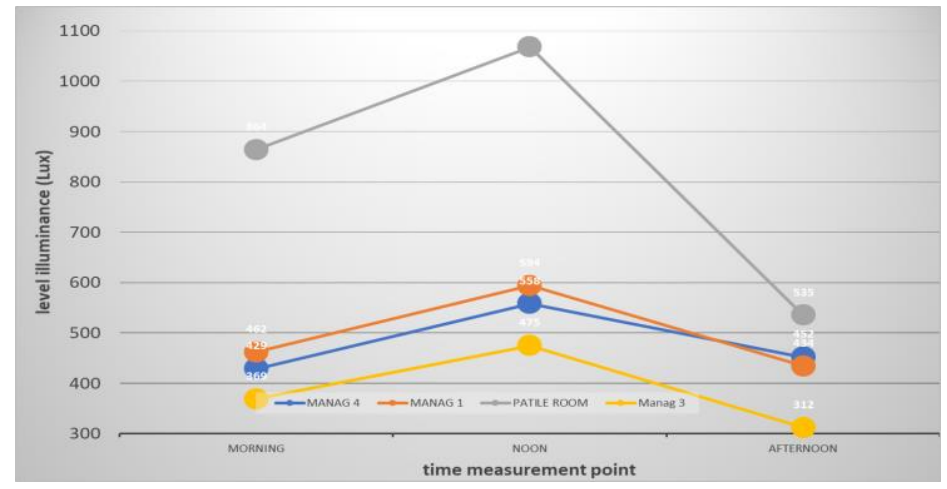

Fig. 11: Mean of level illuminance on four types in workspace

The Figure 11 shows the different levels of illuminance in the east and south orientation spaces. The difference in the distribution of light in the two orientations in the same building and time was 419 lux / 94\% (morning), 492/85\% lux (daytime) and 92/21\% lux (afternoon). The results of the analysis concluded that the light distribution affects the orientation of the building and the depth of space.

\section{E. Natural and Artificial Light Analysis on workspace.}

which is not directly related to the natural light in the Graha Pena Building there is a range of work that is not directly related to not the building envelope, so it requires artificial light in the workspace, as in the following figure 12 . 


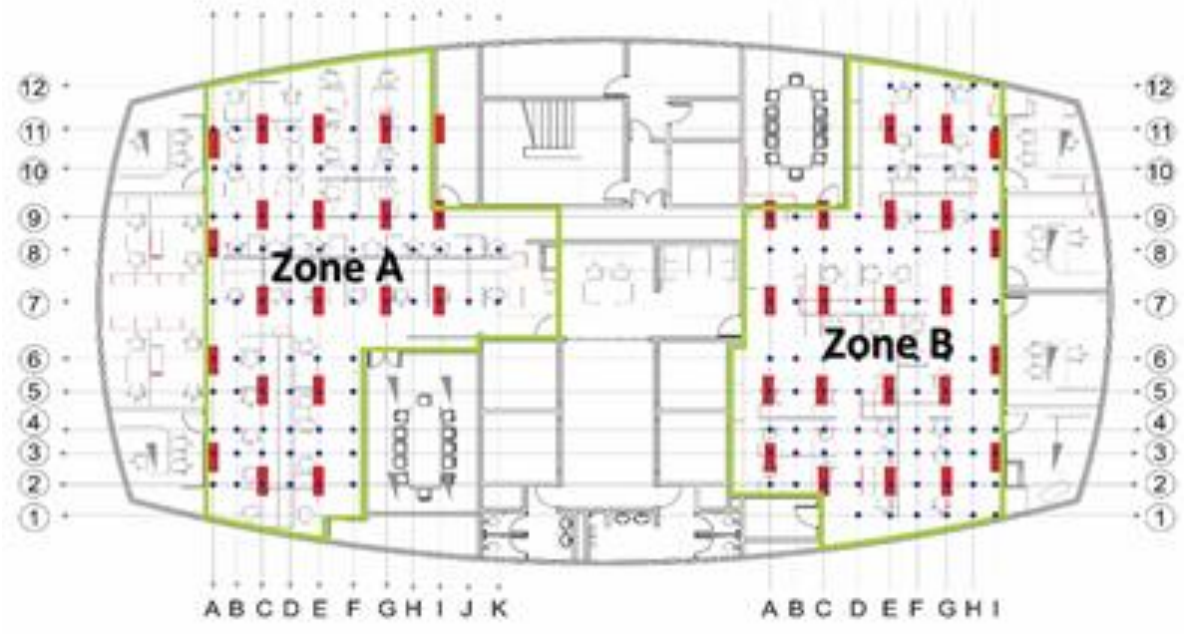

Fig. 12: Mean of level illuminance Room A-D and Zone A-B

The results of local measurements, the lowest light intensity at the measuring point $\mathrm{J} 6$ amount 101 lux to the highest at the measuring point $\mathrm{C} 2$ amount 428 lux. The average intensity under the lamp was 371 lux and between the lamps was 260 lux.
The measurement results of the work area, the intensity of light that has met the SNI-03-65752001 standard recomendation.

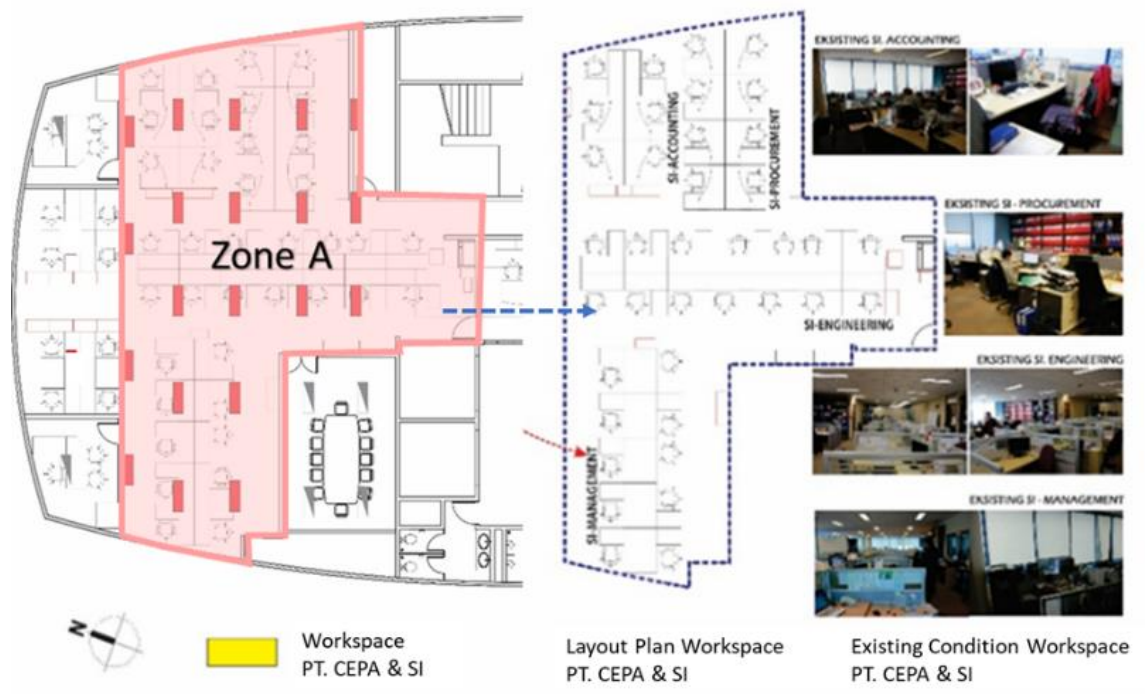

Fig. 13: The results of the measurement of workspace Zone A
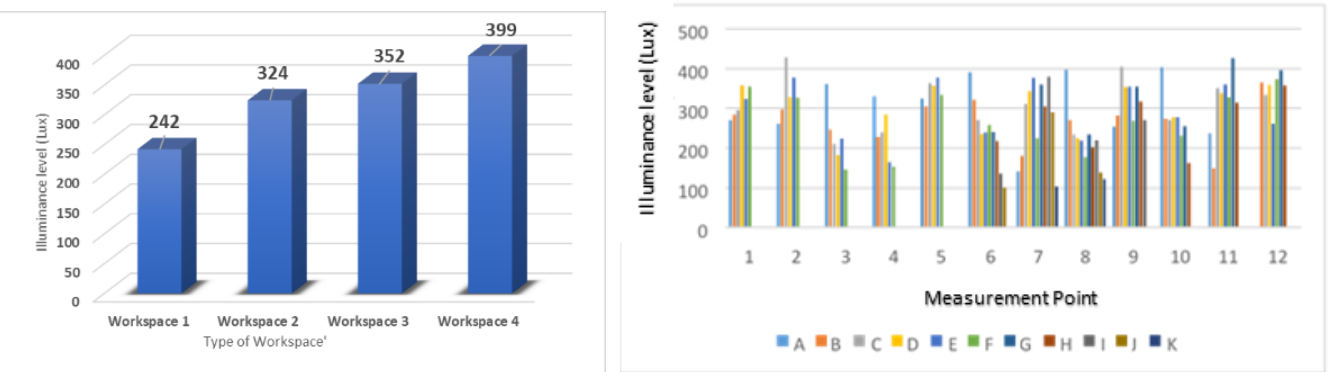

Fig. 14: The results of the measurement of light intensity in the work area (Zone A) 
The results of the measurement of work fields, work groups that meet the SNI-2001 standard are workstation Zone A while those that do not meet the standards are workstation Zone B-others. The intensity of the light working in Zone A. Procurement meets the recommended standard because the placement of the light points is in the middle of the working group so that the intensity of the light spreads evenly.

The results of measurements of local light intensity and work fields in the workspace of workstation room $\mathrm{B}$.

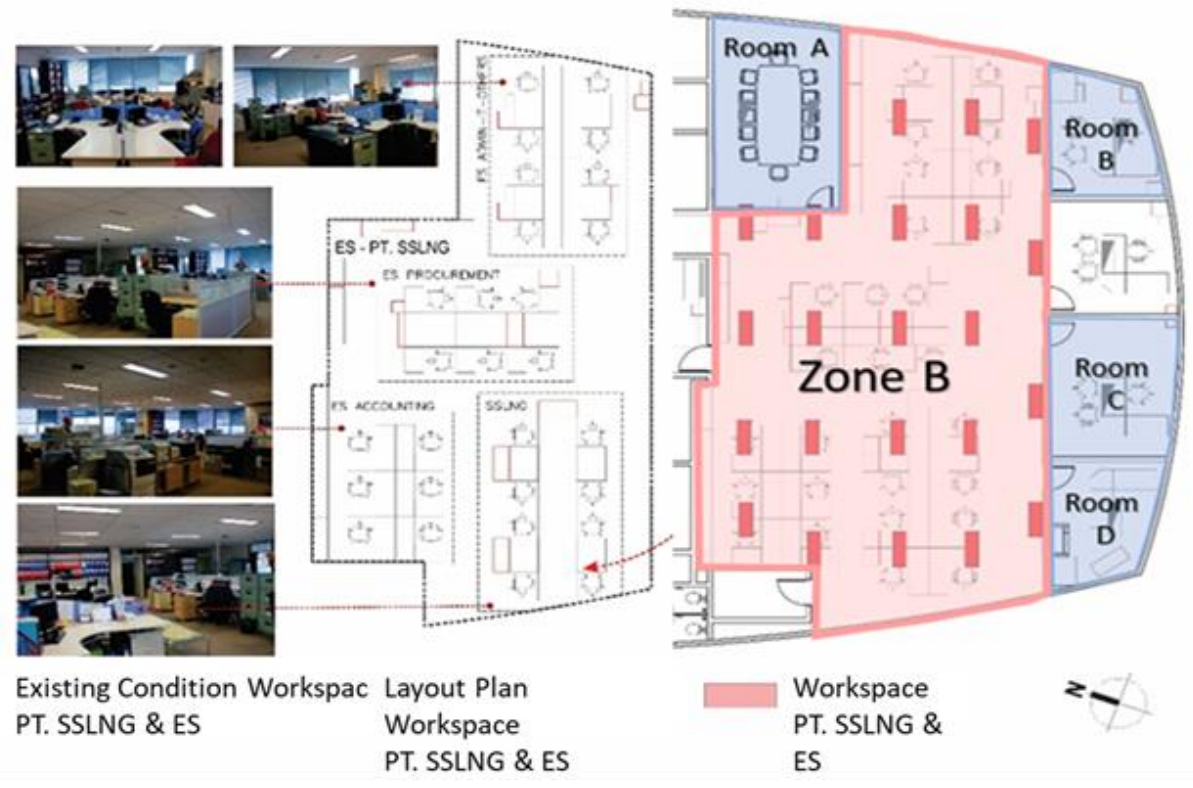

Fig. 15: The condition of the workspace in Zone B

The results of local measurements, the lowest light intensity was at the measuring point A9 is 7 lux and the highest measured I 3 is 430 lux. The average intensity under the lamp is 349 lux and between the lamps is 248 lux. The spread of light intensity in this employee workspace is not uniformity or uneven. One of the reasons is the artificial light design is not good, so the light intensity is uneven.
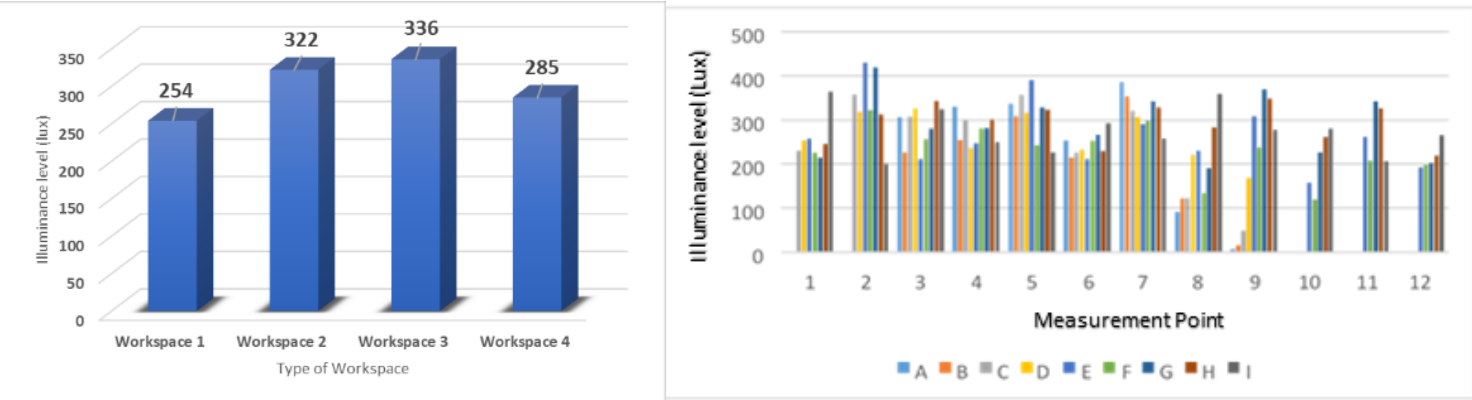

Fig. 16 : The results of the measurement of local light intensity in work area (Zone B)

\subsection{The Design of System Artificial Light in Workspace Graha Pena Building}

The simulation results with a light intensity of 350 lux, the average level illuminance in Type A workspace was between the 276 lux lamp and was 340 lux under the lamps.

While in the workspace of Zone $\mathrm{B}$, the average level of illuminance between the lamps was 260356 lux. Types of lamps used are 36 watt Philips
LED lamps with $2 \times 22$ light points in as much as $2 \times 19$. The distance between the light points is 1.80 meters and 2.60 meters.

In the experimental test, respondents can work well at a light intensity of 150 lux ( Jamala, 2014). From the simulation results, the type of lamps used were 27 watt Philips lamps with 1 x 16 number of lamp points in workspace zone $\mathrm{A}$, and zone $\mathrm{B}$ the number of lamps used was 1 x 16 . The distance between light points was 2.50 meters and 2.80 
meters.

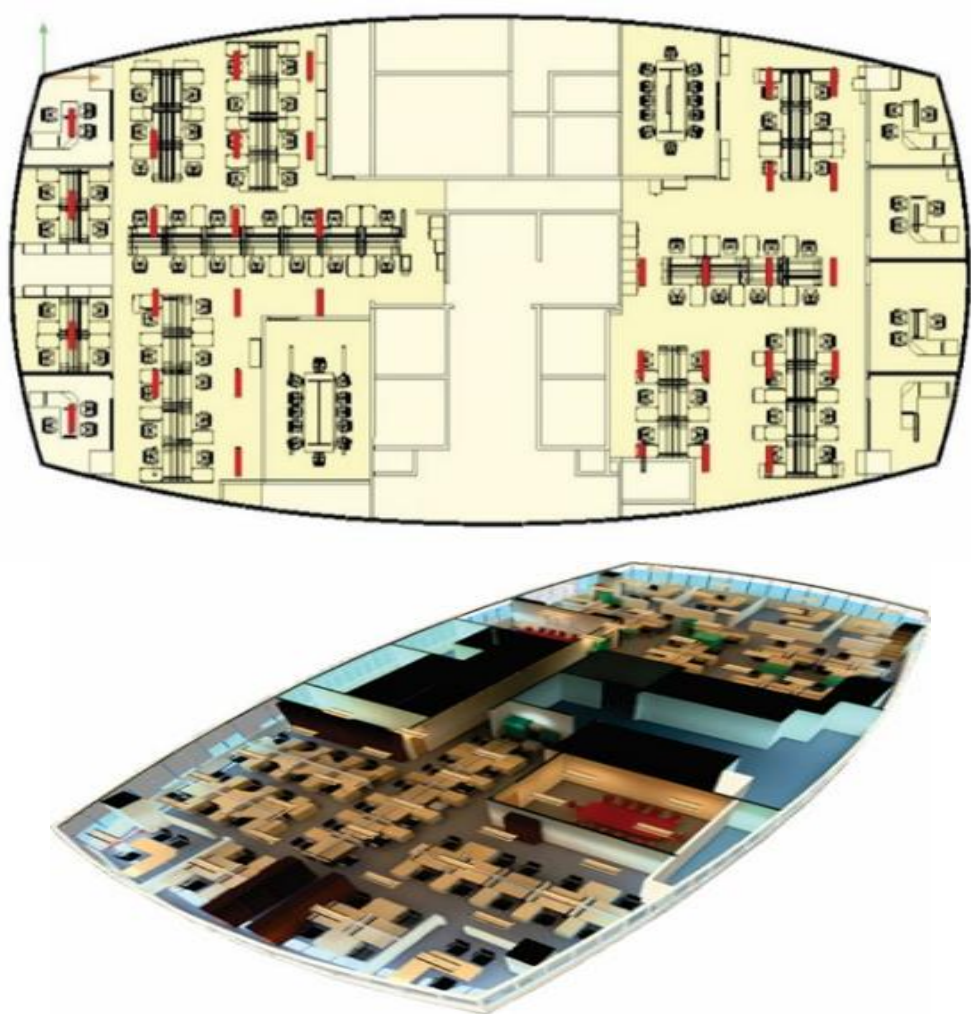

Fig. 17: Design plan of point lampt in Workspace Graha Pena Makassar

\section{CONCLUSION}

The distribution of light affects the orientation of the building and the level of illuminance in a space oriented to the north is higher than in the south. The distribution of light affects the depth of space, and the farther away from the opening in the building envelope, the lower the level of luminance. Placement of light points on the work plane affects the level of illuminance in the work area. Based on this, the planning of the placement of the light points should be designed as well as possible, so that the level of illuminance in the work area is uniformity. The layout design of furniture, especially desktop furniture, needs to be considered so that the level of illuminance in the work area can fulfill visual comfort at work and increase work productivity.

\section{REFERENCES}

[1] Alex, T., (2005). Redefining environmental quality. Building Research and Information, Volume 33, Issue 3, pp 284-286.

[2] Aminuddin Asrul et al. (2012). Thermal Comfort Field Studies in Two Certified Energy Efficiency
Office Building in Tropical Climate. International Journal of Sustaianble Building Technology and Urban Development. Taylor and Francis Publication.

http://dx.doi.org/10.1080/2093761X. 2012.696324

[3] Illuminating Engineering Society (IES) (1977) code for Interioir Lighting (London: IES Lighting Handbook)

[4] Illuminating Engineering Society of North America (IESNA). (2004) American National Standars Practice for Office Lighting (New York: ANSI/IESNA-RP)

[5] Indonesia National Standard 032396-2001. (2001). The Design of The System of Natural Light in The Building (Original in Indonesia language)

[6] Indonesia National Standard 036575-2001. (2001). The Design of The System of Artificial Light in The Building (Original in Indonesia language)

[7] Jakarta Regional Regulation Number 38 (2012) Concerning Green Building. Article 1 p. 3. 
[8] Jamala N, The Effect building Façade on Natural lighting (Case Study; Building Of Phinisi Tower UNM), 7th ICMME, Proceeding by AIP Publishing 978-0-7354-1499-0 (American Institute of Physics), Vol.1831 -No.02006

[9] Jamala N, et al. (2019). Analysis of Illuminance Level on Phinisi Tower Building, Journal Design + Built. Volume 12 no. 1

[10] Jamala, N (2020) Comparison of Building Envelope Models to illuminance Level in Illuminance Level in Phinisi Tower building. IOP Conf. Series: Materials Science and Engineering 875 (2020) 012006

[11] Jamala, N and Rahim, R. (2017). Theory and Application of Visual Comfort. The Publisher of the Makassar State University. (Original in Indonesia language)

[12] Jamala, N. (2017). The Effect building Façade on Natural lighting (Case Study; Building of Phinisi Tower UNM), $7^{\text {th }}$ ICMME, Proceeding by AIP Publishing 978-07354-1499-0 (American Institute of Physics), 1831, 020061(1-8).

[13] Jamala, N., Annajma, N., \& Kusno, A. (2019) Analysis of Daylight Distribution on Building Height and Space Depth. IOP Conf. Series: Material Science and Engineering, 619(1), 012044

[14] Jamala, N., Rahim, R., \& Mulyadi, R. (2019). Analysis of Natural Light Distribution in the Building. IOP Conf. Series: Material Science and Engineering, 619(1), 012024

[15] Jennifer A. et al. (1996). Determinant of Lighting Quality II: Research and Recommendation

[16] Law, J.H.Y., (2002). Reconsider The Design of High-rise Building Towards Sustainable Bioclimatic Architecture. Department of Architecture, The University of Queensland, St. Lucia, Australia.

[17] Lechner, N. (2007). Heating, Cooling, Lighting "Design Method for Architecture", second edition, Jakarta

[18] Nakamura, H., et al. (1985). Luminance Distribution of Intermediate Sky, Journal of light and Vision Environment, 9 (1), 6-
13.

[19] Newsham G. R., et al. (2004). Lighting Design for Open Plan Offices (Canada: Construction Technology) No 62

[20] Rahim R et al,. (2004) clasification of daylight and radiation data into three sky condition by cloud ratio and sunshine duration. Energy and buildings no. 36, 660-666

[21] Rahim, R. (2009). Theory and Application of sky Luminance Distribution in Indonesia National Library (Original in Indonesia language)

[22] Rahim, R., et al. (2004). Classification of Daylight and Radiation Data into Three Sky Condition by Cloud Ratio and Shun Shine Duration. Journal Energy and Building, Elsevier, 36, 660-666.

[23] Rao SP, Aminuddin Asrul et al. (2012). Thermal amd Acoustic Environmental Requirements for Green Buildings Malaysia. Journal of Design and Built Environement. JDBE-Vol 11 No 1 (2012) pp 1-9.

[24] Satwiko, P., (2009). Building Physics. Yogyakarta, Andy ublisher (Original in Indonesia language

[25] Sugianto (1998). Building in Indonesia with a Tropical Climate Humidity from Aspect Building Physics Jakarta (Original in Indonesia language)

[26] Syed Fadzil, S.F. \& Sia, S.J., (2004). Sunlight control and daylight distribution analysis: the KOMTAR case study. Building and Environment, vol.39, pp 713-71.

[27] Shiela Sharif Et al. Implementation Framework of Green Building for Government Building: Menara Kerja Raya Malaysia. Journal of Design and Built Environement. JDBE-Vol 20(1) 24-34, April 2020.

[28] The Design of the System of Natural Light in The Building. (2001). (Original in Indonesia language) Indonesia National Standard 0365752001.

[29] Tommy. (2002). Preferred Luminance Distribution in Working Area

[30] United Nations Environment Programmed (UNEP). (2006). Energy Efficiency guide for industry in Asia. p.1-43. 